\title{
Religious Education, Big Ideas and the study of religion(s) and worldview(s)
}

\author{
Rob Freathy ${ }^{\mathrm{a} 1}$ and Helen C. John ${ }^{\mathrm{b}}$
}

a. Graduate School of Education, University of Exeter, Exeter, UK.

b. Theology and Religion, University of Exeter, Exeter, UK.

\section{Notes on Contributors}

Rob Freathy is Professor of Education in the Graduate School of Education at the University of Exeter, UK.

Helen C. John is an Honorary Research Fellow in the Department of Theology and Religion at the University of Exeter, UK.

\begin{abstract}
This article outlines the 'Big Ideas' approach to curriculum reform, as applied in the 'Principles and Big Ideas of Science Education' project (Harlen 2010). A critical analysis follows of the outcomes of the University of Exeter's 'Identifying Principles and Big Ideas for Religious Education' project, which sought to apply the same approach to Religious Education (RE) in English schools (Wintersgill 2017). This project made great headway in generating 'Big Ideas' to inform and improve the selection and sequencing of RE curriculum content. However, its primary focus on subject content knowledge mean that 'Big Ideas' about epistemology and methodology are lacking. The article recommends an additional focus on multi-disciplinary, multimethodological, inquiry-based, reflexive learning, which would ask why, how, where and by whom our 'knowledge' of religion(s) and worldview(s) is generated. In this regard, the article posits four 'Big Ideas about the study of religion(s) and worldview(s)' to highlight the symbiotic relationship between knowledge and knower, and to reject the false dichotomy between the object of study and method of study. In so doing, it draws upon the theoretical framework underpinning the 'RE-searchers approach' to primary school RE, which correspondingly exemplifies how such ideas can be taught in practice.
\end{abstract}

\section{Keywords}

Religious Education, Big Ideas, RE-searchers, Pedagogy

\footnotetext{
${ }^{1}$ Corresponding author. Email: r.j.k.freathy@exeter.ac.uk
} 


\section{Religious Education, Big Ideas and the study of religion(s) and worldview(s)}

In national policy discourse on Religious Education (RE) in state-maintained primary and secondary schools in England, there has been a lack of focus in recent years on subject content knowledge selection and sequencing. The last report of the government's Office for Standards in Education, Children's Services and Skills (OFSTED) indicates that the RE curriculum is overcrowded, incoherent and confusing for pupils (OFSTED 2013). OFSTED stated that subject leaders 'found it difficult to develop a curriculum for RE that was effective in securing progression, continuity, coherence, breadth and balance in pupils' learning' (2013: 12). This is especially apparent at primary school level as a result of 'poor and fragmented curriculum planning' (OFSTED 2013: 9) which may partly result from 'confusion about the purpose of RE' (2013: 4; see also Conroy et al. 2013). Finding a rationale to underpin decisions about curriculum content selection and sequencing is difficult in such a highly contested and politicised subject (Freathy et al. 2017) which sometimes struggles to demonstrate its relevance and significance to pupils (Wintersgill 2017: Preface). Addressing similar issues in UK Science Education - specifically, the perception that pupils were learning disparate and disconnected facts (Harlen 2010: 1) - a reformulation of the science curriculum has successfully taken place around the notion of 'Big Ideas' (Harlen 2010 and 2015).

In this article, we outline the 'Big Ideas' approach and summarise how it has been used in Science Education. We also describe and examine in detail an attempt to apply the 'Big Ideas' model to RE (Wintersgill 2017). A number of potential criticisms are highlighted which, it is suggested, could be averted if the 'Big Ideas for RE' project developed so as to more closely mirror its Science Education equivalent, specifically by addressing underlying epistemological and methodological assumptions more explicitly. In this regard, we argue that multi-disciplinary, methodologically-orientated, inquiry-led and reflexive learning would complement the proposed 'Big Ideas for RE' by reflecting the diversity of interpretations, methodologies and methods encountered and employed in the study of religion(s) and worldview(s). ${ }^{1}$ Such a focus is highlighted and celebrated in Rob Freathy and Giles Freathy's 'RE-searchers approach' to primary school RE, from which we draw a theoretical framework to underpin the creation of an additional set of RE-specific 'Big Ideas', and which we use to exemplify associated classroom practice. It is argued that the combination of the 'Big Ideas' approach, and critical, dialogic and inquiry-led approaches, of which the 'RE-searchers' is but one, would improve curriculum content selection and sequencing and, in terms of relevance and significance, prepare pupils for what are, in absolute terms, unknown future encounters with religions and worldviews.

\section{Big Ideas and Curriculum Reform}

Recent research in cognitive psychology suggests that a focus on teaching propositional knowledge in place of overarching concepts does pupils of all levels and abilities a disservice (McTighe and Seif 2011: 3-7). Neuroscientific data demonstrates that it not only pupils' understanding (due to a focus on learning information and facts) but also their enjoyment that suffers, as 'there is pleasure in developing understanding' (Harlen 2015: 5). A teacher's role therefore should no longer be conceived as the unidirectional didactic transfer of curriculum content. Constructivist models of education - such as 'Understanding by Design' (Wiggins and McTighe 1998), from which the notion of 'Big Ideas' originates - challenge the oppositional conception of 
teacher and learner, and re-conceive of teaching and learning as cooperative activities. The pupil becomes an active agent in their own learning (with the teacher as a facilitator), developing an appreciation of the 'Big Ideas' ('the architecture of the subject', [GA: 1]). Key to this is inquiry-based learning, based on real world problems that generate curiosity (Harlen 2015: 8, 38-40) and a pattern of formative assessment (Harlen 2010: 45; 2015: 40-43). As an example, in terms of questioning, the emphasis moves from pupils asking questions of the specialist teacher - who then delivers the 'right' answer - to pupils generating their own lines of questioning, which they then pursue in collaboration with others. The role of a 'Big Idea' in such an approach is to become 'a powerful intellectual tool, from which we can derive more specific and helpful understandings and facts', and which 'doesn't end thought, [but] activates it', by raising questions and generating learning (Wiggins 2010; emphasis original). This promotes deep learning of theory and overarching concepts, instead of surface, rote learning of details, and enables pupils to formulate 'Big Ideas' over time (as objects of study) through inquiry (Harlen 2010: 43). This reorientation pursues coherence of information over disparate facts, critical interpretation over uncritical absorption, and questioning and reflexivity over acceptance and unreflective learning. The application of understanding is privileged over knowledge of content, which is apposite given that 'knowledge is expanding exponentially' (Erikson 2002, cited in GA: 2).

Wiggins (2010) explains that 'an idea is big if it helps us make sense of lots of otherwise meaningless, isolated, inert, or confusing facts'. He goes on to suggest that:

A big idea is thus a way of seeing better and working smarter, not just a vague notion or another piece of knowledge. It is more like a lens for looking than another object seen; more like a theme than the details of a narrative; more like an active strategy in your favorite sport or reading than a specific skill. It is a theory, not a detail.

(Wiggins 2010)

A focus on 'Big Ideas' - used interchangeably by some (e.g. Quigley 2013) with the theory of 'threshold concepts' (Meyer and Land 2003) - facilitates deep learning and foregrounds the relevance of the subject to the lives of the pupils, wider society, and the global community (Harlen 2010: 2). These ideas are argued to be 'transformative' in facilitating understanding, 'troublesome' to grasp, 'irreversible' once learned, and 'integrative' in unifying disparate aspects of a subject (Quigley 2013).

The architects of the recent 'Big Ideas' approach to Science Education (Harlen 2010 and 2015) have built on the work of Wiggins and McTighe (1998). The 'Principles and Big Ideas of Science Education' project encompassed '10 Principles of Science Education' and '14 Big Ideas in Science', with the latter being divided into '10 Big Ideas of Science' and '4 Big Ideas about Science' (Harlen 2010). The '10 Principles of Science Education' (Harlen 2010: 6-15) pay significant attention to issues of epistemology and methodology (especially principles 1,3 and 6, which mention 'scientific activity', 'ideas about science', 'scientific capabilities', 'scientific attitudes' and 'scientific inquiry'). Harlen describes the 'Big Ideas in Science' as over-arching concepts that cut across scientific domains, including 'ideas about the world around (such as scale, symmetry, causality, form and function) and ideas about the way in which scientific ideas are generated through human activity' (Harlen 2010: 16). Examples from the 'Big Ideas of Science' include: 'All material in the Universe is made 
of very small particles', and 'Organisms are organised on a cellular basis' (Harlen 2010: Preface. For a brief outline of all of the ideas, see Harlen 2010: 21-23, and for full descriptions, see Harlen 2010: 28-41). The authors also list '4 Big Ideas about Science' as a discipline and mode of inquiry (Big Idea 12 is particularly notable for its foregrounding of the contingency of knowledge: Harlen 2010: 23). Here, certain assumptions under which Science operates are acknowledged:

11. Science assumes that for every effect there is one or more causes.

12. Scientific explanations, theories and models are those that best fit the facts known at a particular time.

13. The knowledge produced by science is used in some technologies to create products to serve human ends.

14. Applications of science often have ethical, social, economic and political implications.

(Harlen 2010: Preface)

To replicate this approach exactly in the context of other curriculum subjects would entail generating 'Big Ideas of the subject' and 'Big Ideas about the subject', that is, ideas about the focus of study and ideas about how such ideas are generated through human activity. Can this approach be applied to RE in English schools?

\section{Big Ideas for Religious Education}

In October 2016, with funding from the St Luke's College Foundation (016J-086), Barbara Wintersgill and Rob Freathy from the University of Exeter, and Michael Reiss from UCL Institute of Education ${ }^{2}$, led a three-day symposium on Dartmoor in the South West of England, involving invited academics, consultants and other RE specialists ${ }^{3}$. The aim was to address long-standing practical issues concerning curriculum content selection, coherence and relevance in RE by applying the theories of Grant Wiggins, Jay McTighe and Lynn Erickson. Divided into working groups, the objective was to develop a manageable number of 'Big Ideas for RE' which teachers, curriculum designers, syllabus writers, textbook authors and other stakeholders could use to determine the selection and prioritization of subject content knowledge. The 'Big Ideas' were expected to have long term relevance, make sense of lots of information and facts, act as lenses to view detailed content, express the central concerns of the subject, and be memorable and transferable to events outside the classroom (Wintersgill 2017: 11). Each 'Big Idea' was to be accompanied by a series of progressive narrative descriptions, using concepts and language appropriate for pupils at each Key Stage, which could be used subsequently to determine the sequencing of curriculum content (following Harlen 2010: 25-27 and 2015: 18-33). Overall, the symposium developed six 'Big Ideas for RE' (see Figure 1) (Wintersgill 2017: 15).

Figure 1. Six Big Ideas for Religious Education

\footnotetext{
${ }^{2}$ Professor Michael Reiss was one of the group of international scientists who produced Principles and Big Ideas of Science Education.

${ }^{3}$ Invited participants: Alan Brine (Former OFSTED National Adviser for RE); Denise Cush (Bath Spa University); Dave Francis (Bath and North East Somerset Standing Advisory Council for RE); Felicity Henchley (Saints' Way Multi-Academy Trust, Cornwall); James Holt (University of Chester); Janet Orchard (University of Bristol); Linda Rudge (Learn, Teach, Lead RE Project Director); Joy Schmack (Liverpool Hope University); Julian Stern (York St John University); and Karen Walshe (University of Exeter).
} 


\section{CONTINUITY, CHANGE AND DIVERSITY}

Religions and non-religious worldviews involve interconnected patterns of beliefs, practices and values. They are also highly diverse and change in response to new situations and challenges. These patterns of diversity and change can be the cause of debate, tension and conflict or result in new, creative developments.

\section{WORDS AND BEYOND}

Many people find it difficult to express their deepest beliefs, feelings, emotions and religious experiences using everyday language. Instead, they may use a variety of different approaches including figurative language and a range of literary genres. In addition, people use non-verbal forms of communication such as art, music, drama and dance that seek to explain or illustrate religious or non-religious ideas or experiences. There are different ways of interpreting both verbal and non-verbal forms of expression, often depending on a person's view of the origin or inspiration behind them. The use of some non-verbal forms of communication is highly controversial within some religious groups, particularly their use in worship or ritual.

\section{A GOOD LIFE}

Many religions and non-religious communities strive to live according to what they understand as a good life. Their members share an understanding as to the sort of characteristics and behaviours a good person will seek to achieve, as well as dealing with what is, or is not, acceptable moral behaviour. People have different ideas about how and why we should lead a good life. The ideal is usually presented in the lives and character of exemplary members. There may be considerable agreement across different religions and non-religious worldviews on some matters, and considerable differences on others. Also, there are often major disagreements over the interpretation and application of moral principles between members of the same religion or worldview.

\section{MAKING SENSE OF LIFE'S EXPERIENCES}

Many people have deeply felt experiences, which they may refer to as being religious or spiritual or simply part of what it means to be human. These experiences may result in people undergoing transformative change and on rare occasions the experience of a single person has led to the formation of a new religion or worldview. Through religious rituals and other practices, people sometimes experience a deep connection with God or gods, nature, their own consciousness or with each other. This can give them a heightened sense of awareness and mystery. Many people find that belonging to religious or non-religious groups with others who share their beliefs, values and traditions gives them a sense of identity and belonging.

\section{INFLUENCE, COMMUNITY, CULTURE AND POWER}

Religious and non-religious worldviews interact with wider communities and cultures. They affect the way communities have come to identify themselves over time by shaping their traditions, laws, political systems, festivals, values, rituals and the arts. The patterns of influence vary significantly in different communities and at different points in time. Some communities are influenced predominantly by one religion. More diverse and plural communities are influenced by several religious and non-religious worldviews. Their appeal to a highly respected authority or vision, 
whether religious or non-religious can lead them to make positive and life-changing contributions to their communities. It can also give them considerable power, which may lead to both positive and negative outcomes.

\section{THE BIG PICTURE}

Religions and non-religious worldviews provide comprehensive accounts of how and why the world is as it is. These accounts are sometimes called 'grand narratives'. They seek to answer the big questions about the universe and the nature of humanity such as 'Does anything exist beyond the natural world?', 'Is there life beyond death?', 'What is the path to salvation?' and 'Do we have one physical life or many?'. These narratives are usually based on approaches to life, texts or traditions, which are taken to be authoritative. People interpret and understand these traditions in different ways.

\section{A Critique of the Big Ideas for RE}

Inevitably, on theoretical and empirical grounds, there are criticisms one might direct at the 'Big Ideas for RE'. ${ }^{2}$ Many of these were raised at the Dartmoor Symposium itself, with participants seeking to mitigate the associated charges, even if they could not do so absolutely. In general, such concerns had to give way to professional pragmatism to ensure concrete outcomes were forthcoming in the time available. The selected criticisms outlined below pose theoretical challenges to the 'Big Ideas for RE' project. They can be averted, as we argue subsequently, if future developments follow more closely the model of the 'Principles and Big Ideas of Science Education' project. This means ceasing to focus so exclusively on the selection, prioritisation and sequencing of the 'Big Ideas of the subject', and incorporating within subject content knowledge explicit consideration of the underlying epistemological and methodological principles (i.e. 'Big Ideas about the subject') (see also Harlen 2010: 18, 20).

In establishing 'Big Ideas' that apply universally across religions and worldviews without exception (following Harlen 2010: 19), it is difficult to avoid potential charges of reductionism or oversimplification to the point of essentialism. The entire endeavour - arguably nomothetic not idiographic - is potentially in conflict with the academic turn towards particularism (see for example, the 'Crisis of Representation' in Anthropology: Clifford and Marcus 1986; Marcus and Fischer 1986), including the ideas that there is no 'objective knowledge in the human sciences' (Clifford Geertz, 2002: 9) and no such thing as a bounded, fixed 'culture' (or, for that matter, religion or worldview). Rather, culture is 'porous and labile' (Brown 2002: 131) and descriptions of fixed culture are 'poesis' and 'invention' (Clifford and Marcus 1986b: 2, 26). Culture(s), religion(s) and worldview(s) are thus not to be seen as 'organically unified or traditionally continuous but rather as negotiated, present processes' (Clifford 1988: 273). Perhaps the endlessly heterogeneous quality of religions and worldviews (which, thereby, renders any 'Big Idea' about religion(s)/worldview(s) perpetually inchoate) is the only legitimate universal - a point suggested (but not fully developed) by the 'Big Idea' entitled 'Continuity, Change and Diversity'. A homogeneous understanding of the phenomenon of religion will fail to equip pupils for encounters with highly-contextualised religious particularities and variations in the future. The polyphony of voices and experiences, including disagreement, needs to be foregrounded in order to avoid the danger of essentialising and constructing an artificial 'Other' (Said 1978). Elsewhere in the 'Big Ideas' literature (e.g. Richardson 2009: 35-36) is to be found a recognition of particularity, as well as a greater focus on self-awareness and reflexivity. 
A related point is the particular vision of 'religion' and 'worldview' underpinning the 'Big Ideas for RE'. Arguably the notion of 'religion' is a Western construct (Asad 1993), and the religious/non-religious binary, as well as the fencing off of 'religion' from 'non-religious worldviews', are of an artificial nature. It would be fair to question whether indigenous traditions/cultures/worldviews would fall into either or both of these categories. The positionality of those, including the present first author, who drew up the 'Big Ideas for RE' (White? Western? Eurocentric? Middle-class? 'Academic'?) inevitably influenced their understandings of the nature of religion(s) and worldview(s). Would diverse grassroots communities, faith traditions and interested specialists across generations and throughout the world share these conceptions? Different groups of people might endorse different sets of 'Big Ideas for RE' based on contrasting theories of religion(s) (e.g. regarding whether they are the product of revelation and religious experience, or whether they are better explained naturalistically). A follower of Feuerbach, Marx or Freud might deem the present list as contentious, inadequate or irrelevant (Thrower 1999). According to what criteria were the 'Big Ideas' deemed valid/credible, and then selected for inclusion? Which were deemed (in)appropriate, and why, for the particular contexts of RE in state-maintained schools with and without religious affiliations? Was there a tendency towards largely uncontroversial empirically-verifiable descriptive statements and away from potentially divisive, abstract explanatory theories? For justifiable political and practical reasons, were what some people might regard as the 'Biggest Ideas' (e.g. about the metaphysical) shunned in favour of merely 'Biggish Ideas' (e.g. about the mundane) around which a consensus could be built?

Fundamentally, the criticisms above relate to how we conceptualise and construct the focus of study in RE. That is why it is so important that, in contrast to the example set by the 'Big Ideas of Science Education' project, the 'Big Ideas for RE' report (Wintersgill 2017) does not integrate consideration of epistemology and methodology (or reflection thereon) into its final list of 'Big Ideas'. Neither does it fully develop its focus on inquiry-led learning, which Harlen notes 'is widely advocated' (2010: 3); an inquiry-based approach characterises every constructivist model that the 'Big Ideas of Science Education' project was drawing upon. The stated 'Principles of Religious Education' do contain purposes and goals promoting, for example, pupils' use of core terms 'whilst understanding their contested nature'; understanding of 'the rationale and consequences of some of the main approaches to the study of religions and nonreligious worldviews'; and ability to 'carry out enquiries into the world of religions and beliefs' (Wintersgill 2018: 5). However, the theories and overarching concepts ('Big Ideas') underpinning these expectations are not articulated. Within the single list of draft 'Big Ideas' to emerge from the Dartmoor Symposium was one idea which explored how people use a variety of methods (e.g. theological, historical, textual, philosophical, socio/psycho-logical) to explore religious and non-religious worldviews, but significantly this was omitted from the final publication. Similarly, while the 'Big Ideas for RE' report devotes a short section ('Managing Big Ideas', pp. 44-46) to 'enquiry-based learning', it does not explain how it conceptualizes the relationship between the process of inquiry involved in answering topical research questions and the 'Big Ideas' that students are intended to grasp through these processes. How can inquiry-led learning be authentic and genuine if the inquiry is designed to teach preordained knowledge and understanding? How can the 'superimposing of selected Big Ideas onto the topic in question' (Wintersgill 2017: 45) promote open-ended, critical 
interpretation, and questioning and reflexivity, rather than the uncritical absorption and acceptance of a particular ontological/epistemological lens? If we wish pupils to be reflective and reflexive in their endeavours, we should acknowledge the subjectivity and positionality of those who generate 'Big Ideas', given that 'objectivity' is an 'anthropocentric illusion' (Jean Piaget, cited in J. L. Jacobs 2002: 89). At the very least, if we accept that knowledge is 'culturally situated' (Hufford 1995: 59), we should encourage pupils to ask themselves about the 'lenses' through which they view the world, and religion(s) and worldview(s) within it.

It is with the intention of contributing constructively to the future development and implementation of the 'Big Ideas' approach in RE that we now consider how the above criticisms can be addressed.

\section{Big Ideas about the Study of Religion(s) and Worldview(s)}

Science's focus on methodology and learning through inquiry is uncontested and explicit both within school and beyond. At the simplest level, pupils undertake practical experiments and reflect on the efficacy and objectivity of their methods. This motivates them by stimulating interest and enjoyment, teaches research skills, enhances the learning of subject content knowledge, provides knowledge and experience of using methodologies and methods, and develops relevant disciplinary attitudes and values, such as open-mindedness, empathy, rigour and criticality (Hodson 1990). Such a focus is not always evident in RE, although epistemological and methodological variety and reflection $i s$ vital in the study of religion(s) and worldview(s): 'As in physics, the very definitions and assumptions that shape the research process partially determine the results. Moreover, the process of observation itself alters that which we observe' (Wilcox 2002: 54).

A multiplicity of hermeneutical approaches, methodologies, and perspectives is deployed in Theology, Religious Studies and cognate disciplines. There is certainly no 'well-defined and uncontested body of knowledge' from which incontrovertible 'Big Ideas' can be derived (Mintrop 2004: 144). Theories developed in these fields of inquiry are often highly contested and self-evidently enthused with ontological, epistemological and methodological assumptions that not all scholars share. These factors must be foregrounded if we are to promote academic honesty and reflective learning in school pupils. OFSTED highlighted a trend in secondary schools of failure to encourage 'an enquiring, critical and reflective approach to the study of religion' (2013: 5) and of offering 'insufficient opportunity for pupils to reflect and work independently' (2013: 6). Indeed, echoing an earlier OFSTED report (2010: 44-46; 2013: 10-11, 17), it identifies as good practice both 'placing enquiry at the heart of learning' and using "'big questions" to give context for enquiry' (2013: 23, 24). Such an approach encourages pupils to be reflexive in their learning, and to acknowledge their own positionality. Shielding them from either the difficulty of selecting and prioritising content in RE or the influence of worldview, location, methodology and method on the outcome of studies of religion(s) and worldview(s) arguably frustrates this aim. We need 'Big Ideas' that highlight aspects of contestation, which point to the variety and influence of epistemological and methodological approach, and which encourage pupils to ask questions of their own locatedness and their own perspective, because meaning is situational and contingent (Geertz 2002: 227). 
The 'Principles and Big Ideas of Science Education' project paid significant attention to issues of epistemology and methodology, both in the 'Principles of Science Education' and the '4 Big Ideas about Science'. To apply the same approach in RE might therefore require the re-naming of the Dartmoor Symposium's 'Big Ideas for RE'. Logically, they should become 'Big Ideas of the study of religion(s) and worldview(s)' and be accompanied by a new set of 'Big Ideas about the study of religion(s) and worldview(s)'. In this regard, referring to 'Big Ideas of/about RE' is unhelpful because (i) RE is not the object of study in RE, (ii) RE is the name of the school subject studied and practised by teachers, teacher trainees and teacher trainers amongst others, and (iii) RE is not the name of the discipline or body of knowledge associated with the study of religion(s) and worldview(s) (see Wintersgill 2017: 45). By contrast, the phrase study of religion(s) and worldview(s) (SORW) can be used to encompass the study of religion as a phenomenon, the study of particular religions or aspects thereof, the study of worldview as a phenomenon, and the study of particular worldviews (religious, spiritual, other, or non-religious) or aspects thereof. It also incorporates the content of what is studied from primary school to higher education and research, as well as the processes in which we are engaged. From Biblical Studies to Anthropology of Religion, from Theology to New Religious Movements, from Comparative Religion to Ancient Languages, as well as every individual religious tradition and/or worldview: all are covered by this statement of what we study and who we are as an academic community. There will be 'Big Ideas of SORW', just as there are 'Big Ideas of Science'. Furthermore, there will be 'Big Ideas about SORW', just as there are 'Big Ideas about Science'. Both 'Big Ideas of/about SORW' can be 'Big Ideas for [use in] RE'.

\section{Four Big Ideas about the Study of Religion(s) and Worldview(s)}

In developing its 'Big Ideas for RE' (what we call 'Big Ideas of SORW'), the Dartmoor Symposium was focused on providing criteria and grounds for subject knowledge content selection and sequencing, thereby deliberately and deftly avoiding longstanding debates between professionals over the nature and purpose of RE, and the most appropriate pedagogical approach. These will inevitably be stirred as we now turn our attention to issues of ontology, epistemology and methodology in an attempt to establish analogues to the 'Big Ideas about Science'. To this end, we have created four possible 'Big Ideas about SORW', drawing and elaborating upon the theories underpinning our critique of the 'Big Ideas for RE' outlined above. We have also drawn upon and refined the theoretical framework behind the 'RE-searchers approach' to primary school RE, which was co-created by the first author (Freathy et al. 2017; Reader and Freathy 2016; Freathy and Freathy 2013b) and which can be used to exemplify what multi-disciplinary, methodologically-orientated, inquiry-led and reflexive learning might mean in practice. The 'Big Ideas about SORW' that we posit seek to provide answers to some fundamental questions that can be asked of all methodologies and pedagogies; that is, what is the focus of study, by whom is it being studied, how is it being studied, and why is it being studied. Although we have striven to produce answers that would be acceptable to a wide constituency, specifically mindful of potential application in multi-faith RE in schools without a religious designation, we recognise that different groups of people might endorse different sets of 'Big Ideas about SORW'. Our selection is intended to be indicative rather than comprehensive, designed primarily to explore the potential of such an approach. Indeed, this selection shares its inchoate status with the six 'Big Ideas for RE' upon which we seek to build. As such, we would welcome the creation of revised, alternative 
or additional 'Big Ideas about SORW', reflecting theoretical, methodological and pedagogical assumptions other than our own.

Our provisional set of 'Big Ideas about SORW' are as follows:

1. Encountering religion(s) and worldview(s): Contested definitions and contexts

There is no uncontested definition of 'religion' or 'worldview', nor is there certainty about the nature of individual religions or worldviews. There is no uncontested definition of what the study of religion(s) and worldview(s) is, or what it should involve. A critical-analytical, empathetic, and inquisitive approach - alongside an awareness of dynamic contexts - is required at all times.

Pupils of SORW are encouraged to engage in empathetic, open-minded, yet criticalanalytical engagement with both familiar and unfamiliar viewpoints, beliefs and practices in their examination of religion(s) and worldview(s) in historical and contemporary contexts. The SORW involves a desire to learn about how others view and experience the world. However, content explored in SORW should not be accepted uncritically and is not uncontested - most of it, if not all, is the product of, and is open to, interpretation. Explanations, theories and models in the study of religion(s) and worldview(s) are those that best fit the facts known at a particular time, but have to take account of spatial, temporal, cultural and other variables.

Effective study of religion(s) and worldview(s) involves acknowledging the difficulty of defining any single religion/worldview, or theory thereof, due to the diverse, dynamic and contested nature of practices and beliefs both within and between groups of adherents. Furthermore, study within this field of inquiry alerts us to the fact that our ability to define religion(s) or worldview(s) is shaped by underlying assumptions about what religion(s) or worldview(s) are. We can generalise across religions and worldviews only if we think there are sufficient similarities between them. We should not do so if we think they are sufficiently distinct. We can talk confidently about religions and worldviews as discrete entities only if we think they do not overlap with other identities, communities, or spaces of belonging/ways of being in the world. Some beliefs and practices may be better described as cultural phenomena, for example, rather than religious phenomena.

As a result of the above, the study of religion(s) and worldview(s) involves sensitivity to the dynamism, negotiation and contestation apparent in:

i. Beliefs and practices (including in the interpretation of texts, language, symbols, traditions, and socio-cultural or political realities);

ii. The cultural, historical and socio-political contexts within which religion(s)/worldview(s) are situated; and

iii. The contexts, theories and frameworks within and through which we study.

\section{Encountering Oneself: Reflexivity, Reflectivity and Positionality}

Who we are (place, era, culture, aspects of identity, etc.) affects - and sometimes determines - what we know about religion(s) and worldview(s). Encounters with unfamiliar peoples, cultures, religions and worldviews assist us in understanding ourselves better. In turn, this equips us better to investigate and understand religion(s) and worldview $(s)$. 
The study of religion(s) and worldview(s) highlights the fact that we perceive the world, others and ourselves through multiple 'lenses', and that we should therefore examine the multiple lenses through which we look. SORW, therefore, involves the foregrounding of the relationship between knower and knowledge, neither of which exist independently of one another. Pupils in SORW examine their own positionality, considering the role of the self in interpreting phenomena related to religion(s) and worldview(s), as well as the study thereof. Encountering other people, other religion(s) and worldview(s), other cultures, and other viewpoint enhances their 'capacity to modify, suspend or otherwise change position when warranted' (QAA 2014: 12).

Reflection involves the pupils pausing to think about their own identity, including their religious affiliation, worldview, and standpoints on various issues in SORW. Reflexivity involves the reinterpretation of oneself, having considered the 'other', with awareness of one's own distinctiveness heightened by the encounter. Engagement with 'others' should enable pupils to reflect on the intersection of aspects of identity (nationality, ethnic identity, gender, sexuality, etc.). They are enabled to explore the coalescence of those aspects in affecting how we experience the world, how we conduct inquiry into religion(s) and worldview(s), as well as the results of our inquiries. Thereby, pupils are prompted to interrogate why they think/believe what they do, and how their composite identity affects their knowledge and view of the world.

The impact of the above for the individual is that SORW 'may be transformative at some level, broadening a person's perspectives and often challenging or changing attitudes'. Whilst this transformation might take the form of spiritual invigoration, a diverse selection of alternatives might include enhanced religio-political awareness and engagement, or the transformation of cultural and intellectual horizons (QAA 2014: 8).

\section{Encountering Methodologies and Methods: Discernment and Diversity}

The study of religion(s) and worldview(s) is inherently multi-disciplinary and methodologically diverse. The disciplinary and methodological approaches taken to the study of a religious phenomenon or worldview will contribute significantly to the results.

The SORW draws upon numerous interrelated subject areas, including textual studies, languages, anthropology, philosophy, ritual studies, historical studies, archaeology, gender studies and ethics. It involves many different theoretical and practical approaches, such as textual criticism, ethnography, phenomenology, material studies, or philology. Pupils of SORW should demonstrate appropriate use of a variety of theories, methodologies and methods of study, engaging in critical analysis of relevant data and arguments. Engaging with a multi-disciplinary, multi-methodological and multi-method field of inquiry, pupils have considerable scope for creative scholarship. Failure to alert them to the diversity in SORW may be interpreted as stifling independent and innovative thinking.

Certain aspects of SORW are better suited to certain methodologies and methods. In terms of engagement with texts, for example, pupils could critically and empathetically deploy a multi-perspectival approach (genre, purpose, meaning, context, translation, etc.) (QAA 2014), which will likely incorporate literary and socio-historical approaches. However, textual interpretation might also involve the study of visual art, as well as cross-cultural readings and reception history. 
As with one's positionality, the theoretical and methodological approach adopted in the SORW has profound implications for the type and scope of data gathered, as well as for its interpretation. 'Knower', 'ways of knowing', and 'theories of knowledge' thus coalesce to precipitate 'knowledge'.

\section{Encountering the 'Real World': Relevance and Transferability}

The study of religion(s) and worldview(s) is a vital tool in gaining knowledge and understanding of the various religions and worldviews in the world, as well as their engagement in contemporary public and private affairs. It offers many transferable skills, which are invaluable in many domains of life experience, including further education and employment.

Both individually and collectively, people are constantly (re)negotiating cultural and religious diversity. Religions and worldviews are encountered in public and private institutions (e.g. political and educational systems). The SORW helps pupils explore and comprehend this complexity and reflect on their own identity and location within this complex system. Knowledge and critical skills (multi-disciplinary and interdisciplinary) attained in SORW are useful in varied careers, such as teaching, ministry, social work, public services, community relations or international relations. Knowledge of religions and worldviews has the potential to contribute to community understanding and development and the avoidance or challenging of prejudices arising from misinformation. Religion affects public debates on topics including international relations, community relations, human rights, social justice, wealth disparity, sustainability, climate change and the impact of the digital revolution. Knowledge and skills can be deployed in relation to these debates as well as in relation to current religious issues (including political, ethical and educational questions).

Having posited four possible 'Big Ideas about SORW' to mirror the four 'Big Ideas about Science' we now need to identify attendant pedagogical principles and procedures by which pupils might learn how to learn about SORW. The 'RE-searchers approach' is used to exemplify these, but no exclusive claim is being made. Other approaches may manifest some or all of the same traits.

\section{The RE-searchers Approach}

Just as the 'Principles and Big Ideas of Science Education' project focused on aligning pupil experience with current scientific knowledge and practice - getting the pupils 'working in a way similar to that of scientists' (Harlen 2010: 3) - so it is possible to conceive of progression pathways from RE in the school classroom to SORW in universities and beyond. Rob Freathy and Giles Freathy's 'RE-searchers approach', for example, invites pupils to become nascent members of the communities of academic inquiry concerned with the multi-disciplinary fields of Theology and Religious Studies, so as to 'enter into the kind of informed, critical and sensitive dialogues which are at the heart of academic study of religion(s)' (2013b: 159). Not only do pupils learn about religion(s), but also they learn 'how to learn about religion(s)' (2013b: 161). Thereby, their approach promotes pupil awareness of interpretations, methodologies and methods, and their influence on the outcome of study. In so doing, it puts 'Big Ideas about SORW' on the map: 
Through a dialogic, critical and inquiry-based approach, curriculum subjects can balance consideration of (i) representations of the world and/or phenomena for analysis; (ii) interpretations, methodologies and methods; and (iii) personal reflection and reflexivity (Freathy et al., 2015, p. 8). In such an approach, teachers and pupils respectively can be re-conceptualised as 'pedagogical bricoleurs' and 'bricolage researchers', negotiating a complex, dense, reflexive, collage-like curriculum that represents their own and other people's images, understandings and interpretations of the subject matter.

(Freathy et al. 2017)

Drawing on critical theory, and Bakhtin's notions of dialogism, polyphony and unfinalizability, the 'RE-searchers approach' promotes practical, participative and interactive methods of inquiry-led, reflective learning, with an attendant focus on multiple interpretations, methodologies and methods, whilst spotlighting the political dimensions of knowledge construction, dissemination and acquisition (Freathy et al. 2017). It is underpinned by the idea that 'it is not the responsibility of RE teachers to promote any particular theory or definition of religion or a specific mode of interpretation, but to facilitate discussion and evaluation of a plurality of perspectives' (2013b: 161). This approach signals the danger of advancing 'Big Ideas for RE' that represent a singular list of seemingly incontrovertible theories about religion(s), and mitigates it by encouraging teachers and pupils to attend to the diversity and effect of epistemological and methodological approaches in SORW.

To operationalise the principles underpinning their approach, Freathy and Freathy have developed four cartoon characters, collectively known as the 'RE-searchers', in whose shoes primary school pupils can metaphorically investigate topics and on whose methods they can reflect thereafter (2013a: 4). The characters are 'caricatures of some of the pedagogical approaches outlined in Grimmitt (2000)' (2013b: 162), and are 'partially inspired by Edward De Bono's Six Thinking Hats (1985)' (2013a: 4). Each character holds different assumptions about the nature of religion(s); has a preferred way of approaching the study of religion(s); and employs particular methods of inquiry: See-the-story Suzie (narrator/interpretation explorer), Debate-it-all Derek (philosopher/critic), Ask-it-all Ava (interviewer/communicator), and Have-a-go Hugo (participator/experiencer) (Freathy et al. 2017). In practice, pupils are asked to 'step in and out of character, and engage in dialogic conversation about (i) the religious phenomenon under study, (ii) the 'RE-searcher' character through whose eyes it has been viewed (including their implicit ontological, epistemological and methodological assumptions), and (iii) the pupils' skills, dispositions and worldviews as researchers' (2013b: 163). Re-conceived as joint researchers, pupils work in collaboration with their teachers and peers to co-construct knowledge through a 'collage' of pedagogies that go some way to reflect the extended 'family of methodologies, methods, theories, concepts, skills, competencies and subject matter' evident in Theology, Religious Studies and cognate disciplines in higher education and research (Freathy et al. 2017). Such multi-disciplinary and multi-perspectival inquiry is designed to enable pupils 'to resist attempts by dominant knowledge to colonise their thinking' (Freathy et al. 2017). Indeed, failing to foreground the multiplicity of epistemologies and methodologies in SORW risks 'infringing the liberal principle, and human right, of freedom of belief' that is entrenched in the underlying principles of RE provision in English statemaintained schools without a religious affiliation (Moulin 2009: 153). 
When applied in the primary school classroom (see Freathy 2016; Freathy and Freathy 2016; and Freathy et al. 2015 for pedagogical procedures and curriculum resources), Freathy and Freathy report considerable success with pupils finding lessons memorable, being challenged to think about the subject matter and approaches to it in a different way, and appreciating the effect worldview, methodology and method can have on perceptions of religion(s) (2013a: 4-5). The approach has also been applied successfully in secondary school RE, in schools with or without religious affiliation, and in other (particularly humanities) subjects (Freathy et al. 2017).

Moreover, such an approach might be employed to engage pupils, as a community of investigators, in direct discussion of, and inquiries into, the 'Big Ideas of SORW' as explicit hypotheses to be examined and tested. Arguably, this transparency and promotion of criticality is preferable to the 'Big Ideas of SORW' merely being used by teachers, curriculum designers, syllabus writers, textbook authors and other stakeholders as criteria for selecting and sequencing curriculum content. This is because curriculum content chosen and ordered in accordance with the 'Big Ideas of SORW' will then implicitly and covertly endorse underlying theories which pupils will have little option but to passively receive and accept. On the part of pupils, the treatment of 'Big Ideas of SORW' as hypotheses to be tested (or even re-framed as 'Big Questions') would facilitate (i) consideration of curriculum content selection (in terms of avenues to be explored, rather than 'indisputable and immutable' knowledge [Freathy et al. 2017]); (ii) critical reflection on the validity and credibility of the 'Big Ideas' themselves (or the answers posited to the associated 'Big Questions'); and (iii) discussion of relevant philosophical, epistemological and methodological questions. This would complete the application of the Science model - Big Ideas of and Big Ideas about - in combination with an inquiry-led, constructivist pedagogy. It would also potentially enable pupils subsequently to move beyond any provisional set of 'Big Ideas of SORW' - through the application of critical and creative thinking, and undertaking of original rigorous inquiries - towards the construction of their own new or revised 'Big Ideas' about religion(s) and worldviews(s).

\section{Conclusion}

In this article, we have attempted to outline the University of Exeter's 'Identifying Principles and Big Ideas for RE' project (Wintersgill 2017) which sought to apply, within the context of RE, the approach advocated by the 'Principles and Big Ideas of Science Education' project (Harlen 2010). The primary purpose was to generate criteria to inform and improve RE curriculum content selection and sequencing. The advantages of the 'Big Ideas' approach are that pupils gain a holistic appreciation of interconnected, overarching, core ideas within the subject, rather than engaging with an atomised (and necessarily exclusionary) body of content identified by either religion or theme, for example. The theories help pupils make meaning from the minutiae, to identify connections, and to see overarching patterns. The implication of a reorientation toward 'Big Ideas' is the requisite change in pedagogical tack, moving toward inquirybased learning, and 'the corollary ... that the breadth has to be reduced' (Harlen 2010: $3)$.

We have also suggested here that the 'Big Ideas for RE' developed by the Dartmoor Symposium (what we have called 'Big Ideas of SORW') have limitations, not least that they neglect to promote reflection on epistemological and methodological issues. If we are to draw on all of the benefits of a 'Big Ideas' approach, and follow the lead of the 
'Principles and Big Ideas of Science Education' project, RE must be characterised by multi-disciplinary, multi-methodological, inquiry-based, reflexive learning in which pupils engage in collaborative investigations (Shulman and Sherin 2004: 137). In this regard, we used the exemplar of Rob Freathy and Giles Freathy's 'RE-searchers approach' to primary school RE because it focuses teachers' and pupils' minds on issues such as positionality, reflexivity, and co-construction of knowledge in the study of religion(s) and worldview(s). This is a field of inquiry wherein both the object of study and the interpretations, methodologies and methods employed are diverse, contested, and contingent. It is to higher education and research contexts in the SORW that we hope to draw a trajectory from primary RE, through such initiatives as the 'REsearchers approach'. Overall, to be analogous to the Science Education model, both 'Big Ideas of' and 'Big Ideas about' the study of religion(s) and worldview(s)' should be identified and endorsed.

\section{Notes}

1. We use 'inquiry' rather than 'enquiry' in the context of 'inquiry-led learning'. Although often used interchangeably, 'enquiry' has connotations of asking for or requesting pre-existing information, while 'inquiry' is often associated with researching or investigating to generate new knowledge (Baumfield and Higgins 2008). 2. In accordance with our emphasis on reflexivity and positionality in the study of religion(s) and worldview(s), it is appropriate we acknowledge our own locations as authors. Rob Freathy was the lead applicant securing funds for the 'Identifying Principles and Big Ideas for Religious Education' project, a core participant at the Dartmoor Symposium, a contributor to the final report, and the manager of its publication. His past and present contributions to the ongoing development and implementation of the 'Big Ideas' project reflect a preference for critical, dialogic and methodologically/hermeneutically-orientated RE. Helen John is a former RE teacher and now New Testament specialist, focusing particularly on inter-/trans-disciplinary and cross-cultural perspectives and methods, including anthropological fieldwork and investigation of indigenous worldviews in Southern Africa. Amongst other things, she is currently working with Rob Freathy on various RE-related projects, which conceive of the study of religion(s) and worldview(s) as a multi-disciplinary, multimethodological and multi-perspectival field, which should be imbued with reflexivity and led by inquiry.

\section{Acknowledgements}

The 'Identifying Principles and Big Ideas for Religious Education' project was supported by the St Luke's College Foundation (016J-086). The 'RE-searchers: A critical dialogic approach to Religious Education in primary schools' project was supported by the Culham St. Gabriel's Trust and Hockerill Education Foundation.

\section{References}

Asad, T. 1993. Genealogies of Religion: Discipline and Reasons of Power in Christianity and Islam. Baltimore, London: The Johns Hopkins University Press.

Baumfield, V. and S. Higgins. 2008. 'Child And The Curriculum In The $21^{\text {st }}$ Century: The Relationship Between Enquiry And Inquiry In The Classroom'. Paper presented at the annual meeting of the American Education Research Association, New York, March 24-28.

Bransford, J., A. Brown, and R. Cocking, eds. 2001. How people learn: Brain, mind, experience, and school. Washington, DC: National Research Council. 
Brown, K. M. 2002. 'Writing about "The Other," Revisited' in Personal Knowledge and Beyond, edited by J. V. Spickard, S. Landres and M. B. McGuire, 127-133. New York: New York University Press.

Clifford, J. 1988. The Predicament of Culture: Twentieth Century Ethnography, Literature and Art. Cambridge, MA: Harvard University Press.

Clifford, J. and G. E. Marcus, eds. 1986a. Writing Culture: The Poetics and Politics of Ethnography. Berkeley, CA: University of California Press.

Clifford, J. and G. E. Marcus, eds. 1986b. 'Introduction' in Writing Culture: The Poetics and Politics of Ethnography edited by James Clifford and George E. Marcus, 1-26. Berkeley, CA: University of California Press.

Conroy, J. C., D. Lundie, R. A. Davis, V. Baumfield, L. P. Barnes, T. Gallagher, T. Gallagher, K. Lowden, N. Bourque, and K. Wenell. 2013. Does Religious Education Work? A Multidimensional Investigation. London: Bloomsbury.

Erickson, H. L. 2002. Concept-Based Curriculum and Instruction: Teaching beyond the facts. London: Sage.

Freathy, G. 2016. The RE-searchers Approach: A quick start guide with exemplar units of work and activities. Exeter: University of Exeter.

Freathy, G., R. Freathy, J. Doney, K. Walshe and G. Teece. 2015. The RE-searchers: a New Approach to Primary Religious Education. Exeter, University of Exeter.

Freathy, G. and R. Freathy. 2016. 'RE-searchers'. Available at: http://www.reonline.org.uk/re-searchers/ [Accessed 22 ${ }^{\text {nd }}$ June 2017].

Freathy, R. and G. Freathy. 2013a. 'RE-searchers: a dialogic approach to RE in primary schools.' REsource 36(1): 4-7.

Freathy, R. and G. Freathy. 2013b. 'FORUM: Initiating Children into Hermeneutical Discourses in Religious Education: A Response to Rachel Cope and Julian Stern.' Journal for the Study of Spirituality 3(2): 156-167.

Freathy, R., J. Doney, G. Freathy, K. Walshe, and G. Teece. 2017. 'Pedagogical bricoleurs and bricolage researchers: The case of Religious Education.' British Journal of Educational Studies. 65(4), 425-443. DOI: 10.1080/00071005.2017.1343454.

GA (Geographical Association): 'Using Key Concepts and Big Ideas to plan Curriculum Sequences for the Where Will I Live Project?' Available online at: http://www.geography.org.uk/projects/wherewillilive/resources/keyconcepts/\#top

[Accessed $7^{\text {th }}$ June 2017].

Geertz, A. W. 2002. 'As the Other Sees Us: On Reciprocity and Mutual Reflection in the Study of Native American Religions.' in Personal Knowledge and Beyond edited by J. V. Spickard, S. Landres and M. B. McGuire, 225-236. New York: New York University Press.

Geertz, C. 2002. 'An Inconstant Profession: The Anthropological Life in Interesting Times.' Annual Review of Anthropology 31:1-19.

Harlen, W. ed. 2010. Principles and Big Ideas of Science Education. Trieste: IAP.

Harlen, W. ed. 2015. Working with Big Ideas of Science Education. Trieste: IAP.

Hodson, D. 1990. 'A critical look at practical work in school science.' School Science Review 70(256): 33-40.

Hufford, D. J. 1995. 'The Scholarly Voice and the Personal Voice: Reflexivity in Belief Studies.' Western Folklore 54: 57-76.

Jacobs, J. L. 2002. 'Transitional Identities: Self, Other, and the Ethnographic Process.' in Personal Knowledge and Beyond edited by J. V. Spickard, S. Landres and M. B. McGuire, 88-99. New York: New York University Press.

Marcus, G. E. and M. M. J. Fischer. 1986. Anthropology as Cultural Critique: An Experimental Moment in the Human Sciences. Chicago, IL: Chicago University Press. 
McTighe, J. and E. Seif. 2011. 'A Summary of Underlying Theory and Research Base for Understanding by Design.' Available online at: https://jaymctighe.com/wordpress/wp-content/uploads/2011/04/UbD-Research-

Base.pdf [Accessed $7^{\text {th }}$ June 2017].

Meyer, J. H. F. and R. Land. 2003. 'Threshold concepts and troublesome knowledge: linkages to ways of thinking and practising.' in Improving Student Learning: Theory and Practice - Ten Years On edited by C. Rust, 412-424. Oxford: Oxford Centre for Staff and Learning Development.

Mintrop, H. 2004. 'Fostering constructivist communities of learners in the amalgamated multi-discipline of social studies.' Journal of Curriculum Studies 36(2): 141-158. DOI: 10.1080/0022027032000142500

Newmann, F., A. Bryk, and J. Nagaoka. 2001. Authentic intellectual work and standardized tests: Conflict or coexistence? Chicago: Consortium on Chicago School Research.

OFSTED. 2010. 'Transforming religious education.' Available online at: http://dera.ioe.ac.uk/1121/1/Transforming\%20religious\%20education.pdf [Accessed $16^{\text {th }}$ June 2017].

OFSTED. 2013. 'Religious Education: realising the potential.' Available online at https://www.gov.uk/government/publications/religious-education-realising-the-

potential [Accessed 17th June 2017].

Quality Assurance Agency. 2014. Subject Benchmark Statement: Theology and Religious Studies. Gloucester: Quality Assurance Agency for Higher Education.

Quigley, A. 2013. 'Designing a New Curriculum - What are your 'Big Ideas'?' Available online at: http://www.theconfidentteacher.com/2013/11/designing-newcurriculum-big-ideas/ [Accessed $7^{\text {th }}$ June 2017].

Reader, J. and R. Freathy. 2016. 'Technology and education: theoretical reflections exemplified in Religious Education.' Journal of Beliefs and Values 37(3): 320-333.

Richardson, R. 2009. Holding Together: Equalities, Difference and Cohesion: Guidance for School Improvement Planning. Stoke on Trent: Derbyshire County Council and Trentham Books.

Said, E. W. 1978. Orientalism. London, UK: Routledge and Kegan Paul.

Shulman, L. S. and M. G. Sherin. 2004. 'Fostering communities of teachers as learners: disciplinary perspectives.' Journal of Curriculum Studies 36(2): 135-140. DOI: 10.1080/0022027032000135049

Spickard, J. V., J. S, Landres, and M. B. McGuire. eds. 2002. Personal Knowledge and Beyond: Reshaping the Ethnography of Religion. New York, NY and London, UK: New York University Press.

Wiggins, G. 2010. 'What is a Big Idea?' Available online at: https://www.authenticeducation.org/ae bigideas/article.lasso?artid=99 $\quad$ [Accessed $7^{\text {th }}$ June 2017].

Wiggins, G. and J. McTighe. 1998. Understanding by Design. Alexandria, VA: Association for Supervision and Curriculum Development.

Wilcox, M. M. 2002. 'Dancing on the Fence: Researching Lesbian, Gay, Bisexual, and Transgender Christians', in Personal Knowledge and Beyond edited by J. V. Spickard, S. Landres and M. B. McGuire, 47-60. New York: New York University Press.

Wintersgill, B, ed. 2017. Big Ideas for Religious Education. Exeter: University of Exeter. 